\title{
Learning in honeybees as a function of amount of reward: Control of delay
}

\author{
YOUNGLIM LEE and M. E. BITTERMAN \\ University of Hawaii, Honolulu, Hawaii
}

\begin{abstract}
Six experiments on learning in honeybees were prompted by the possibility that results previously attributed to a difference in amount of reward (20- versus 5- $\mu$ l drops of sucrose solution presented on colored targets) might be due at least in part to a difference in delay of reward attendant on greater difficulty in locating the 5- $\mu$ l drops. Substantial reduction in the diameter of the targets, which was designed to facilitate location of the drops, impaired discrimination of the colors, perhaps because their salience was reduced in the process (Experiment 3). White dots used to mark the location of the drops on larger targets also impaired discrimination of the colors, which presumably were overshadowed by the dots (Experiments 1,2, and 4). That the dots did not serve merely to equate delay but were themselves discriminated was demonstrated in Experiment 5, which produced as well the first indication of an effect of amount of reward uncontaminated by the possibility of differential delay: Animals trained with a 5- $\mu$ l drop on a dotted target of one color and a drop of the same size on an undotted target of a second color preferred the dotted target, but animals trained with a $5-\mu l$ drop on a dotted target of one color and a 20- $\mu$ l drop on an undotted target of a second color preferred the undotted target. In Experiment 6 , with odors substituted for the colors on the assumption that they were less likely to be overshadowed by the dots, what could be interpreted as a pure amount effect was found again. Aside from their relevance to questions about the role of amount of reward, the results have some interesting implications for the theory of discriminative learning in honeybees.
\end{abstract}

In recent experiments on the role of amount of reward in the learning of honeybees (Buchanan \& Bitterman, 1988, 1989; Lee \& Bitterman, 1990), individual foragers were trained with successively presented targets of two different colors that contained 5- or 20- $\mu$ l drops of sucrose solution, after which color preference was measured in a choice test. What conceivably may happen under such circumstances is that one color is associated with one reward and the other color with the other reward-the two associations differing not only in their first terms but also in their second terms, or significates-and that choice between the colors is determined by the relative attractiveness of the two remembered or "represented" rewards. Nowhere in the rather substantial set of data already available is there any indication, however, that amount of reward is represented as such. What the data suggest instead is that the significates of the two associations are the same (say, sweetness), and that the effect of amount of reward is on associative strength. All of the data can in fact be simulated accurately on the assumption that associative strength grows at a rate increasing with amount of reward to an asymptote independent of amount of reward, with choice between the colors determined by relative associative strength. The most direct support for an

This research was supported by Grant BNS-8709785 from the National Science Foundation. Requests for reprints should be addressed to M. E. Bitterman, Békésy Laboratory of Neurobiology, 1993 EastWest Road, Honolulu, HI 96822. equal-asymptote, nonrepresentational interpretation is provided by the finding that a strong preference for the $20-\mu l$ color as compared with the 5- $\mu$ l color develops early in training and then tends to disappear as the training continues.

Although there is no indication that honeybees learn about amount of sucrose, an experiment on successive contrast (Couvillon \& Bitterman, 1984) suggests that they do learn about concentration of sucrose. The difference is perhaps to be understood in terms of the different ways in which concentration and amount are detected. Concentration is detected immediately upon contact with a solution, but amount may be detected only as feeding is prolonged-unless, of course, visual size plays some role. The possibility of visual size as a source of immediate differential reinforcement can be discounted on the ground that the animals fail to show a preference for the larger of the two drops when permitted to choose between them (Lee \& Bitterman, 1990). A more likely influence of visual size - on delay of reward-is suggested by the finding that a $20-\mu$ drop is located more readily than a $5-\mu l$ drop when the animals are trained to choose between two identical targets of which only one contains a drop of sucrose (Walker, Lee, \& Bitterman, 1990). An association between color and sucrose may develop more rapidly with a 20- $\mu$ l drop than with a 5- $\mu$ l drop only because of closer contiguity between perception of the color and the initial taste of sucrose, with a common asymptote approached as the animals learn somehow to locate the small drop more quickly in the course of continued training. 
The present experiments were prompted by the hypothesis, which it is convenient to call the "delay" hypothesis, that delay of reward was a critical factor in our previous experiments on amount of reward. Unfortunately, the time between the perception of a color and contact with the sucrose cannot be measured directly, there being no way of knowing when the color is perceived. Our approach instead was to look for a training method uncontaminated by the possibility of amount-correlated delay.

\section{EXPERIMENT 1}

The technique used in this experiment and in all but one of the following experiments (which are summarized in Table 1) was to mark the location of the drop of sucrose presented on each target. As in previous work, that location was the center of the target, but now the center was indicated with a small dot of sharply contrasting white paint in order to help the animals find it more quickly. In the training, the $20-\mu \mathrm{l}$ and 5- $\mu$ l targets were presented equally often at a frequency which, in the absence of the dots, was known to produce a clear preference for the larger. To the extent that the preference was due to a difference in delay rather than in amount of reward, it was expected that the preference would be reduced by the dots if they did in fact equate delay.

\section{Method}

Subjects. The subjects were 30 honeybees (Apis mellifera) from our own hives situated near the laboratory. All were experimentally naive.

Procedure. Individual honeybees were pretrained to fly from the hive to the laboratory and drink from a large drop (about $100 \mu \mathrm{l}$ ) of $50 \%$ sucrose solution on a target that was set on the sill of an open laboratory window. The target was a plastic disk, $5 \mathrm{~cm}$ in diameter and $1 \mathrm{~mm}$ thick, that was (nominally) half-blue and halforange ( $180^{\circ}$ of each color). An animal selected at random from a group of foragers at a feeding station equipped with a jar of $10 \%-12 \%$ sucrose solution was captured in a match box, carried to the sill, and placed on the target. There it was permitted to drink its fill (during which time it was marked with a spot of lacquer) and then to fly back to the hive. Typically, the animal would return to the laboratory in a few minutes, continuing to shuttle back and forth between the hive and the sill as long as food was available there. If the marked bee did not return to the sill after its first placement, it was picked up at the feeding station (where it usually could be found) and placed again on the target. The pretraining ended with the animal's second return to the sill of its own accord.

In the experiment proper, three groups of 10 animals each were trained in 12 visits and then tested. Arriving from the hive on each training visit, the animals of Group ND-ND found a target like the pretraining target, but all blue or all orange, containing either a $5-\mu l$ or a $20-\mu l$ drop of $50 \%$ sucrose solution at its center. After ingesting the sucrose, the animal would fly up from the target, hovering over the sill while the target was quickly removed and replaced with another target, again either blue or orange and containing either 5 or $20 \mu \mathrm{l}$ of the sucrose solution. The second target was quickly

Table 1

Summary of Experimental Procedures and Results

\begin{tabular}{|c|c|c|c|c|c|c|c|}
\hline \multirow[b]{2}{*}{ Experiment } & \multirow[b]{2}{*}{ Conditions } & \multirow[b]{2}{*}{ Groups } & \multicolumn{2}{|c|}{ Training Stimuli } & \multicolumn{2}{|c|}{ Test Stimuli } & \multirow[b]{2}{*}{ Results } \\
\hline & & & $\mathrm{A}$ & B & $\mathrm{A}$ & B & \\
\hline \multicolumn{8}{|c|}{$5-\mathrm{cm}$ Colors, Single Window } \\
\hline 1 & $\begin{array}{l}30 \mathrm{~A}, 30 \mathrm{~B} \text { trials } \\
\text { same } \\
\text { same }\end{array}$ & $\begin{array}{l}\text { ND-ND } \\
\text { D-ND } \\
\text { D-D }\end{array}$ & $\begin{array}{l}20 \\
20 \mathrm{D} \\
20 \mathrm{D}\end{array}$ & $\begin{array}{l}5 \\
5 D \\
5 D\end{array}$ & D & D & $\begin{array}{l}A>B \\
A=B \\
A=B\end{array}$ \\
\hline 2 & $\begin{array}{l}12 \mathrm{~A}, 24 \mathrm{~B} \text { trials } \\
\text { same }\end{array}$ & $\begin{array}{l}\text { ND-ND } \\
\text { D-ND }\end{array}$ & $\begin{array}{l}20 \\
20 \mathrm{D}\end{array}$ & $\begin{array}{l}5 \\
5 D\end{array}$ & & & $\begin{array}{l}A=B \\
A=B\end{array}$ \\
\hline \multicolumn{8}{|c|}{ 1-cm Colors, Single Window } \\
\hline 3 & $\begin{array}{l}30 \mathrm{~A}, 30 \mathrm{~B} \text { trials } \\
12 \mathrm{~A}, 24 \mathrm{~B} \text { trials }\end{array}$ & $\begin{array}{l}\text { ND1 } \\
\text { ND2 }\end{array}$ & $\begin{array}{l}20 \\
20\end{array}$ & $\begin{array}{l}5 \\
5\end{array}$ & & & $\begin{array}{l}A=B \\
A=B\end{array}$ \\
\hline \multicolumn{8}{|c|}{ 7.5-cm Colors, Two Windows } \\
\hline 4.1 & $\begin{array}{l}24 \mathrm{~A}, 24 \mathrm{~B} \text { trials } \\
\text { same } \\
\text { same }\end{array}$ & $\begin{array}{l}\text { ND-ND } \\
\text { D-ND } \\
\text { D-D }\end{array}$ & $\begin{array}{l}20 \\
20 \mathrm{D} \\
20 \mathrm{D}\end{array}$ & $\begin{array}{l}5 \\
5 D \\
5 D\end{array}$ & D & D & $\begin{array}{l}A>B \\
A=B \\
A>B\end{array}$ \\
\hline 4.2 & $\begin{array}{l}12 \mathrm{~A}, 24 \mathrm{~B} \text { trials } \\
\text { same }\end{array}$ & $\begin{array}{l}\text { D-ND } \\
\text { D-D }\end{array}$ & $\begin{array}{l}20 \mathrm{D} \\
20 \mathrm{D}\end{array}$ & $\begin{array}{l}5 D \\
5 D\end{array}$ & D & D & $\begin{array}{l}A=B \\
A=B\end{array}$ \\
\hline 5 & $\begin{array}{l}24 \mathrm{~A}, 24 \mathrm{~B} \text { trials } \\
\text { same } \\
\text { same }\end{array}$ & $\begin{array}{l}20-5 D \\
5-5 D \\
\text { 5-5D-R }\end{array}$ & $\begin{array}{l}20 \\
5 \\
5\end{array}$ & $\begin{array}{l}5 D \\
5 D \\
5 D\end{array}$ & $\mathrm{D}$ & $\begin{array}{l}\mathrm{D} \\
\mathrm{D}\end{array}$ & $\begin{array}{l}A>B \\
A<B \\
A=B\end{array}$ \\
\hline \multicolumn{8}{|c|}{ Odors, Two Windows } \\
\hline 6.1 & $\begin{array}{l}24 \mathrm{~A}, 24 \mathrm{~B} \text { trials } \\
\text { same }\end{array}$ & $\begin{array}{l}\text { ND-ND } \\
\text { D-ND }\end{array}$ & $\begin{array}{l}20 \\
20 D\end{array}$ & $\begin{array}{l}5 \\
5 \mathrm{D}\end{array}$ & & & $\begin{array}{l}\mathrm{A}>\mathrm{B} \\
\mathrm{A}>\mathrm{B}\end{array}$ \\
\hline 6.2 & 24 A trials & D-D,ND & $5 \mathrm{D}$ & & Dvs.ND & & $\mathrm{ND}<\mathrm{D}$ \\
\hline
\end{tabular}

Note $-A$ and $B=$ colors or odors, 5 and $20=$ drops of sucrose solution (in $\mu$ l), $D=$ dot marking the location of the sucrose. The tests were made with $10-\mu$ l drops of water, their locations marked (D) or unmarked (blank). In the group designations, which reflect both training and testing conditions, ND $=$ no dot. 
replaced by a third, and so on, until the replete animal left of its own accord for the hive. For 5 of the 10 subjects, the blue targets always contained $20 \mu \mathrm{l}$ of sucrose and the orange targets $5 \mu \mathrm{l}$, with the opposite true for the remaining subjects. The two targets were presented in balanced quasirandom sequences over the 12 visits, during which the animals averaged $29.020-\mu$ l trials and $28.75-\mu \mathrm{l}$ trials. (The procedure was such, of course, that the number of trials with each target could not be fixed exactly by the experimenter, since it depended to some extent on the behavior of the animalson where in the series of trials given on each visit the animal broke off and returned to the hive; the intake of sucrose, which averaged $50-60 \mu \mathrm{l}$, varied from animal to animal and from visit to visit.) To randomize stimuli other than color, the targets used on each visit were drawn at random (with washing before replacement) from groups of blue and orange targets. The training of Groups D-D and D-ND was exactly the same as for Group ND-ND, except that at the center of each target there was a white dot, $4 \mathrm{~mm}$ in diameter, on which the drop of sucrose was deposited. For Group D-D, there were, on the average, $30.620-\mu \mathrm{l}$ trials and $30.75-\mu \mathrm{l}$ trials; for Group D-ND, the corresponding means were both 30.9 .

After the last training visit, each animal returned from the hive to find a pair of fresh targets, one blue and the other orange, set $10 \mathrm{~cm}$ apart in a lateral arrangement on the window sill. For Groups ND-ND and D-ND, the targets had no dots, but dotted targets were used for Group D-D. For half the animals in each group, the target of the $20-\mu \mathrm{l}$ color was on the left, and, for the remaining animals, it was on the right. Each target now contained a 10- $\mu$ l drop of tap water (unacceptable, and distinguishable from the sucrose solution only by taste). Upon encountering water on one of the targets, the animal would leave it, then return to it or go to the other, leave again, return again (often only briefly, with no attempt to drink), and so forth, the interval between successive responses increasing as the test continued. All actual contacts with each target, however brief, during a 10-min extinction period were recorded by the experimenter, who pressed one of two hand-held switches that activated counters programmed to print stored frequencies at $30-\mathrm{sec}$ intervals. The duration of the test was $10 \mathrm{~min}$. (These temporal parameters - the 30-sec cumulation interval and the 10 -min test duration-are used routinely in our laboratory.)

\section{Results}

In Figure 1, the test performance of the three groups is plotted in terms of the mean cumulative number of responses to each color in successive 30 -sec intervals. An overall analysis of variance-based in accordance with our routine practice on uncumulated 30 -sec scores in 2.5-min blocks-yielded neither a significant group effect $[F(2,27)$ $=1.04, p=.3687]$ nor a significant stimulus $(20 \mathrm{vs}$. $5 \mu \mathrm{l})$ effect $[F(1,27)=1.98, p=.1710]$, but it did yield a significant block effect $[F(3,81)=68.32, p<.0001]$ and a significant group $\times$ stimulus $\times$ block interaction $[F(6,81)=2.44, p=.0321]$. Separate analyses yielded a significant stimulus effect $[F(1,9)=12.14, p=.0069]$, a significant block effect $[F(3,27)=20.78, p<.0001]$, and a significant stimulus $\times$ block interaction $[F(3,27)$ $=8.43, p=.0004]$ for Group ND-ND; for Group DND, a significant block effect $[F(3,27)=14.10$, $p<.0001]$, but neither a significant stimulus effect $(F<1)$ nor a significant stimulus $\times$ block interaction $(F<1)$; and again for Group D-D, a significant block effect $[F(3,27)=36.98, p<.0001]$, but neither a significant stimulus effect $(F<1)$ nor a significant stimulus $\times$ block interaction $(F<1)$.

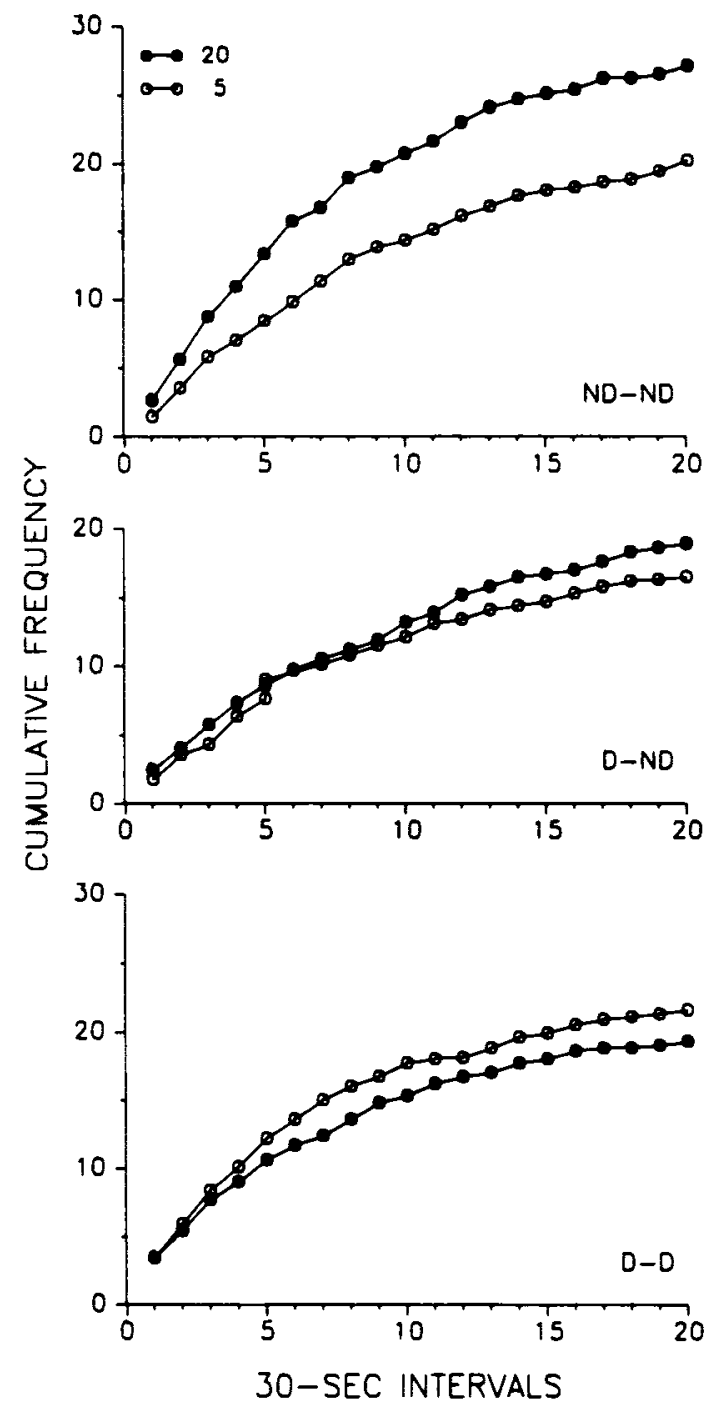

Figure 1. Mean number of responses in extinction to the 20- and $5-\mu$ l colors by the three groups of Experiment 1.

The failure of discrimination in Group D-D suggests that the failure of discrimination in Group D-ND cannot be attributed to the difference between its training and testing conditions. The failure of discrimination in both groups trained with dots seems instead to support the conclusion that the preference for the $20-\mu \mathrm{l}$ color shown by the group trained without dots was due entirely to a difference in delay of reward rather than in amount of reward. Before we can conclude that differences in preference previously attributed to differences in amount of reward should be attributed to differences in delay, it is necessary, however, to consider the possibility that the dots do not serve merely to reduce delay of reward, but are themselves discriminative stimuli that overshadow color (Couvillon, Klosterhalfen, \& Bitterman, 1983). The similar extinction performance of Groups D-D and D-ND cannot be taken as evidence that the dots acquired little associative strength, because the level of responding to 
separate alternatives in these choice tests is more closely related to their relative than to their absolute associative strengths (Couvillon \& Bitterman, 1989). In our various experiments on amount of reward, we have had to be content thus far with predictions of relative preference on the basis of relative strength (Buchanan \& Bitterman, 1988, 1989; Lee \& Bitterman, 1990).

\section{EXPERIMENT 2}

Our purpose in Experiment 2 was to try to distinguish between the delay and overshadowing interpretations of the role of the dots in training. The procedure was to train one group of animals under our standard (ND) conditions with twice as many presentations of the 5- $\mu$ l color as of the 20- $\mu$ l color. It was known from previous work (Buchanan \& Bitterman, 1988) that no preference for either color would be produced by such training, the difference in frequency of reward compensating almost exactly for the difference in amount of reward. A second group was trained in the same way, except with dotted targets. If delay rather than amount of reward was at work under our standard conditions, and if the dots served only to equate delay, a preference for the more frequently rewarded color would develop, but a color preference would not develop if the dots simply overshadowed the colors.

\section{Method}

Subjects. The subjects were 24 foragers from our own hives, all experimentally naive.

Procedure. The animals were pretrained in the same way as those in Experiment 1. The training also was the same, except for the number of visits and the number of trials with each color. The training of each animal was continued until the number of trials with the $20-\mu$ l color approximated 12 and the number of trials with the $5-\mu$ l color approximated 24 . These frequencies were chosen on the basis of previous work (Buchanan \& Bitterman, 1988). For Group ND-ND (trained without dots), the mean number of visits required was 7.3 , in which the mean number of $20-\mu$ l trials was 12.1 and the mean number of $5-\mu l$ trials was 24.0 ; for Group DND (trained with dots), the corresponding means were 7.0, 12.1, and 24.4. Then both groups were tested with undotted targets. Target color and amount of reward were balanced throughout.

\section{Results}

The performance of the two groups in the extinction test is plotted in Figure 2 in terms of the mean cumulative number of responses to each color in successive 30 sec intervals. Analysis of variance yielded neither a significant group effect $(F<1)$ nor a significant stimulus effect $(F<1)$, nor a significant group $\times$ stimulus interaction $(F<1)$. The absence of a color preference in Group ND-ND was, of course, expected from previous work. The novel result of this experiment is that Group DND did not show the preference for the more frequently rewarded 5- $\mu$ l color that was to be expected on the assumption that the dots would simply equate delay of reward. Whatever the effect of the dots on delay, the performance of animals trained with dots suggests that they

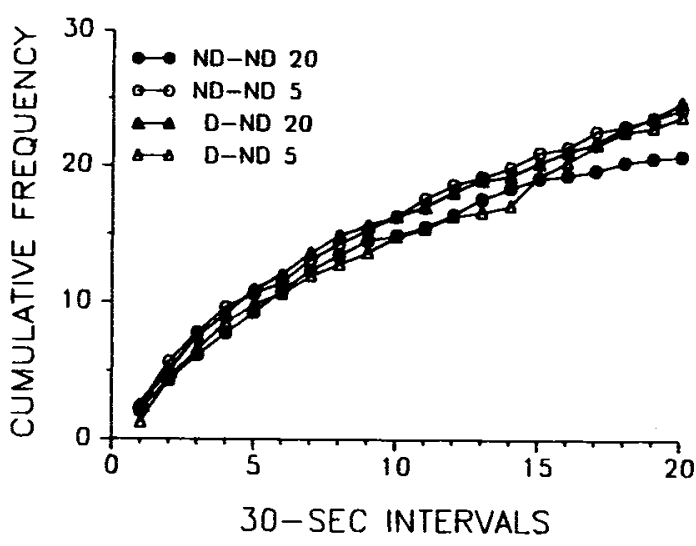

Figure 2. Mean number of responses in extinction to the 20- and 5- $\mu$ l colors by Groups ND-ND and D-ND of Experiment 2.

also have some sort of perceptual effect that impairs discrimination of the colors.

\section{EXPERIMENT 3}

In Experiment 3, we attempted to minimize whatever amount-correlated difference in delay of reward there might be by using much smaller targets than before. The new targets, made of the same materials as the old, were disks $1 \mathrm{~cm}$ rather than $5 \mathrm{~cm}$ in diameter. One group of animals (Group ND1) was treated exactly like Group NDND of Experiment 1, tested after 12 training visits with the same number of $20-\mu l$ and 5- $\mu$ l trials. A second group (ND2) was treated exactly like Group ND-ND of Experiment 2 , tested after twice as many trials with the 5- $\mu$ l color as with the $20-\mu \mathrm{l}$ color. If the results for amount of reward obtained with the larger targets really were due to differences in delay of reward, and if delay was equated by the use of much smaller targets, it was expected that there would be no preference for either color in the first group and a preference for the 5- $\mu$ l color in the second. On the amount hypothesis, there should be a preference for the $20-\mu 1$ color in the first group and no preference for either color in the second.

\section{Method}

Subjects. The subjects were 22 foragers from our own hives, all experimentally naive.

Procedure. Except for the size of the targets, the pretraining, training, and testing were the same as for the ND-ND groups in Experiments 1 and 2 . The 10 animals of Group ND1 had 12 training visits, in the course of which they averaged $29.220-\mu$ and 29.4 $5-\mu$ trials. In an average of 6.3 training visits, the 12 animals of Group ND2 averaged 12.0 20- $\mu$ l trials and $24.05-\mu$ l trials.

\section{Results}

In Figure 3, the test performance of the two groups is plotted in terms of the mean cumulative number of responses to each color in successive 30 -sec intervals. Analysis of variance yielded neither a significant group 


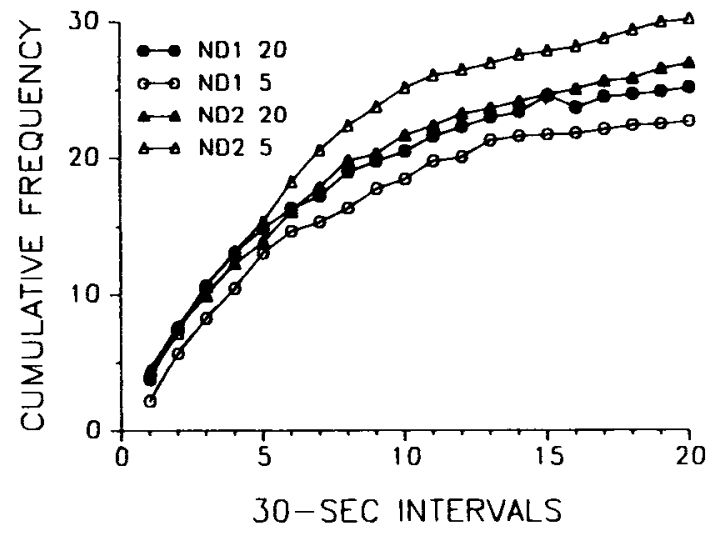

Figure 3. Mean number of responses in extinction to the 20- and $5-\mu l$ colors by Groups ND1 and ND2 of Experiment 3.

effect $[F(1,20)=1.79, p=.1957]$ nor a significant stimulus effect $(F<1)$, nor a significant group $\times$ stimulus interaction $[F(1,20)=1.95, p=.1779]$. The simplest interpretation of these results is that color was not a very salient feature of such small targets and failed in consequence to acquire any substantial amount of associative strength.

\section{EXPERIMENT 4}

In Experiment 4, we returned to the use of dots to mark the location of reward and thus to reduce differential delay, but under conditions designed to increase the salience of the colors and thus to reduce overshadowing. One change was to increase the size of the targets, which were now $7.5 \mathrm{~cm}$ in diameter. A second change was to use two adjacent windows for the training and to require the animals to fly from one to the other on successive trials, a technique developed previously out of interest in measuring response latency (Lee \& Bitterman, 1990). The hope here was that a longer approach to a larger area of color that might be detected before the dot itself was detected would result in better conditioning of the color. For animals trained without dots, of course, the increase in the size of the targets might even be expected to increase the difference in amount-correlated delay.

The experiment had two parts, which will be referred to as Experiments 4.1 and 4.2. In Experiment 4.1, three groups were trained in the same way as the three groups (ND-ND, D-ND, and D-D) in Experiment 1, and the logic also was the same: To the extent that the ND preference for the 20- $\mu$ l color was due to a difference in delay, the preference of animals trained with dots would be less if the dots served to equate delay. In Experiment 4.2, as in Experiment 2, there were twice as many trials with the $5-\mu \mathrm{l}$ color as there were with the $20-\mu \mathrm{l}$ color. Here, two groups were trained with dots and tested with or without dots (D-D and D-ND), and the expectation from the delay hypothesis was, as before, a preference for the more frequently rewarded color.

\section{Method}

Subjects. The subjects were 44 foragers from our own hives, all experimentally naive.

Procedure. Instead of a single training window as in Experiments 1-3, we used two immediately adjacent windows (each $55 \mathrm{~cm}$ wide and $55 \mathrm{~cm}$ high) separated by a thin $(2-\mathrm{cm})$ wooden partition around which the animal was required to fly from one window to the other. In the pretraining, which otherwise was much the same as before, experience with both windows was given. An animal was started on a pretraining target in one window (equally often the left or the right) and permitted to feed to repletion. When it returned from the hive to that window, it was picked up after a few seconds of feeding, placed on a pretraining target in the alternative window, and again permitted to feed to repletion. On subsequent visits, a pretraining target was alternated between windows, and the pretraining ended after the animal had returned twice to each window.

Half the training visits began in each window (in quasirandom orders), and the trials of each visit were alternated regularly between the two windows. After the animal had taken the sucrose on a target found, say, in the left window, that target was removed, and the animal was required to fly for the next trial to the right window, in which another target had in the meantime been placed, and so forth. As expected from previous work in this situation (Lee \& Bitterman, 1990), the shuttling was slow to begin with but improved sharply as training continued. In extinction, two targets were placed in one of the two windows, the left for half the animals in each group and the right for the rest. All other aspects of the procedure were the same as in the reference Experiments 1 and 2, except that all targets, including the pretraining targets, were $7.5 \mathrm{~cm}$ in diameter

In Experiment 4.1, three groups of animals were treated as were Groups ND-ND, D-ND, and D-D in Experiment 1, with one exception: Instead of 12 visits, each animal was permitted enough visits to bring the number of trials with each color close to 24 , which was the scheduled number of trials with the 5- $\mu$ l color in Experiment 4.2. Group ND-ND $(n=12)$ averaged 9.8 visits, $24.120-\mu 1$ trials, and $24.05-\mu \mathrm{l}$ trials. The corresponding means were 9.8 visits with 24.0 and 24.0 trials for Group D-ND $(n=8)$, and 10.6 visits with 23.9 and 24.1 trials for Group D-D $(n=8)$. In Experiment 4.2, one group of animals was treated as was Group D-ND in Experiment 2 , which had twice as many trials with the 5- $\mu$ l color as with the $20-\mu \mathrm{l}$ color. A second group (D-D) was treated in the same way, except dotted targets were used also in the extinction test. Group DND $(n=8)$ averaged 6.5 visits, $23.85-\mu l$ trials, and $12.020-\mu \mathrm{l}$ trials. The corresponding means for Group D-D $(n=8)$ were 6.4 visits with 24.1 and 12.0 trials.

\section{Results}

In Figure 4, the test performance of the three groups of Experiment 4.1 is plotted in terms of the mean cumulative number of responses to each color in successive 30$\mathrm{sec}$ intervals. An overall analysis of variance did not yield a significant group effect $[F(2,25)=2.82, p=.0783]$, but did yield a significant stimulus effect $[F(1,25)=$ $16.19, p=.0005]$, a significant block effect $[F(3,75)=$ $46.68, p<.0001]$, and a significant group $\times$ stimulus $\times$ block interaction $[F(6,75)=2.52, p=.0281]$. Separate analyses yielded a significant stimulus effect $[F(1,11)=16.39, p=.0019]$, a significant block effect $[F(3,33)=25.75, p<.0001]$, and a significant stimulus $\times$ block interaction $[F(3,33)=8.59, p=.0002]$ for Group ND-ND; for Group D-ND, a significant block effect $[F(3,21)=15.05, p<.0001]$, but neither a significant stimulus effect $[F(1,7)=1.83, p=.2177]$ nor a 

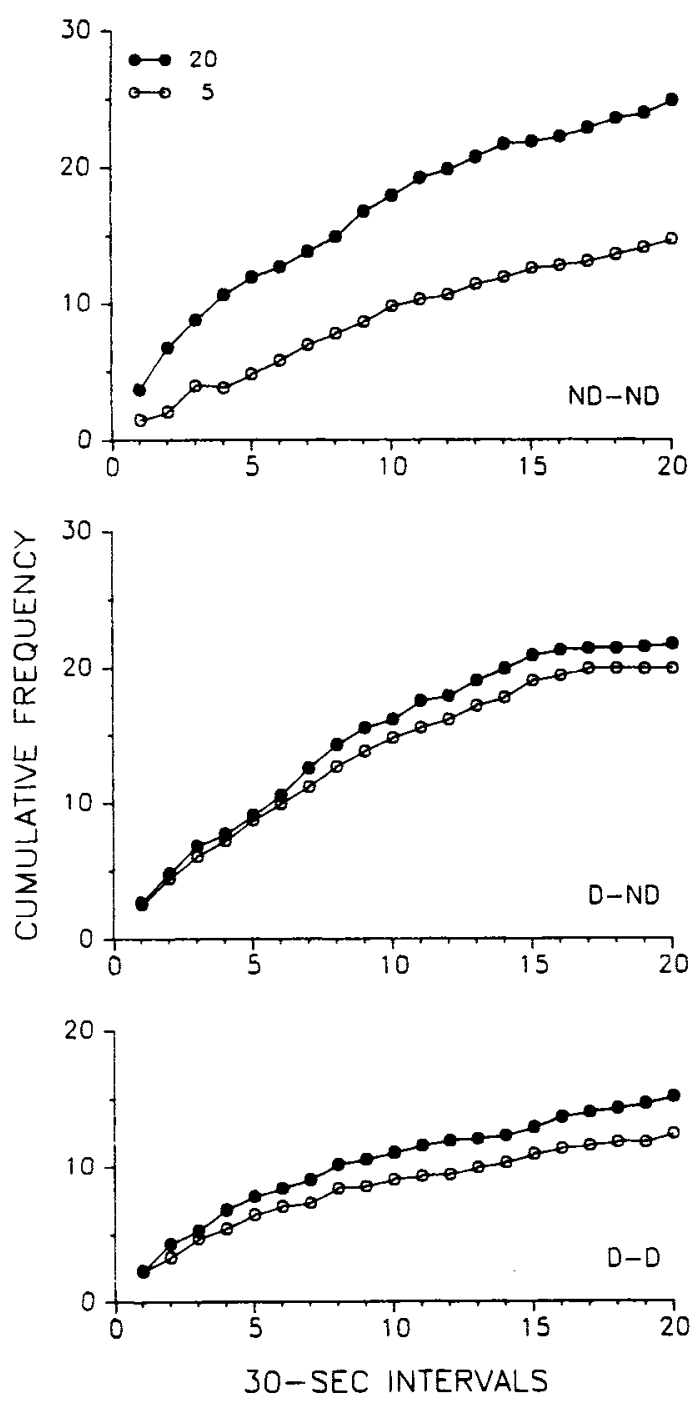

Figure 4. Mean number of responses in extinction to the 20- and $5-\mu$ l colors by the three groups of Experiment 4.1.

significant stimulus $\times$ block interaction $(F<1)$. For Group D-D, however, the small stimulus effect was significant $[F(1,7)=6.27, p=.0407]$ and so also was the block effect $[F(3,21)=11.55, p=.0001]$, although the stimulus $\times$ block interaction was not $(F<1)$. Under the conditions of this experiment, then, the dots did not entirely rule out discrimination of the colors, which nevertheless was substantially less in Group D-D than in Group ND-ND $[F(1,18)$ for the group $\times$ stimulus interaction $=5.32, p=.0332$ ]. It still is unclear from the results whether the dots serve to equate delay of reward or to overshadow the colors.

In Experiment 4.2, as in Experiment 2, there was no difference in the test performance of the two groups and no evidence of discrimination. The extinction curves are shown in Figure 5. Analysis of variance yielded a significant block effect $[F(3,42)=34.29, p<.0001]$, but neither a significant stimulus effect nor a significant group $x$ stimulus interaction, nor a significant interaction of group $\times$ stimulus $\times$ block $(F<1$ in each case). The possibility that the dots serve, not to equate delay of reward, but simply to overshadow color, still cannot be discounted.

\section{EXPERIMENT 5}

The novel feature of Experiment 5 was that only one of the two colors was dotted, which meant that the dot could only increase the discriminability of the targets (Color A plus dot vs. Color B alone). One of three groups was trained and tested with dotted 5- $\mu$ l and undotted 20$\mu l$ colors, which pitted the smaller reward with reduced delay (plus whatever inherent advantage a dotted target might have) against the larger reward. To assess the contribution of the dot, a second group was trained and tested with dotted and undotted 5- $\mu$ l colors. To distinguish between the effect of the dot in training and its effect on performance in extinction, a third group, trained like the second, was tested with the dotted training color undotted and the undotted training color dotted. The number of training trials with each color was the same.

\section{Method}

Subjects. The subjects were 36 foragers from our own hives, all experimentally naive.

Procedure. The two-window training procedure and large targets of Experiment 4 were used again here. Although the twowindow procedure gave much the same results as did the onewindow procedure and was more difficult to execute, it seemed intuitively to be a better procedure, because the targets were in troduced in the absence of the subject and were approached from a greater distance. For Group 20-5D $(n=12)$, the $20-\mu l$ color was undotted and the 5- $\mu \mathrm{l}$ color was dotted both in training and in extinction (which was carried out as usual in a 10-min choice test with a 10- $\mu$ l drop of water on each target). The animals averaged 9.8 training visits in which there were, again on the average, 24.120$\mu \mathrm{l}$ trials and 23.95- $\mu \mathrm{l}$ trials. For Group 5-5D $(n=12)$, the procedure was the same as for the first group, except that the targets of both colors contained $5 \mu$ l of sucrose, which meant that 24 trials with each color were given in a smaller number of visits. The mean values were 4.5 visits, 24.1 undotted $5-\mu \mathrm{l}$ trials, and 24.1 dotted $5-\mu \mathrm{l}$ trials. For Group 5-5D-R $(n=12)$, trained in the same way, the corresponding means also were the same, but color and dot were oppositely paired in the extinction test (the dotted training color now undotted, and the undotted training color now dotted).

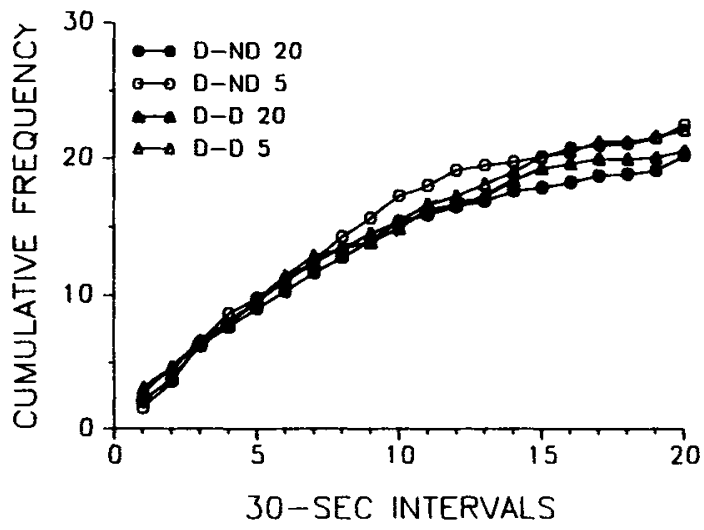

Figure 5. Mean number of responses in extinction to the 20- and 5- $\mu$ l colors by Groups D-ND and D-D of Experiment 4.2. 

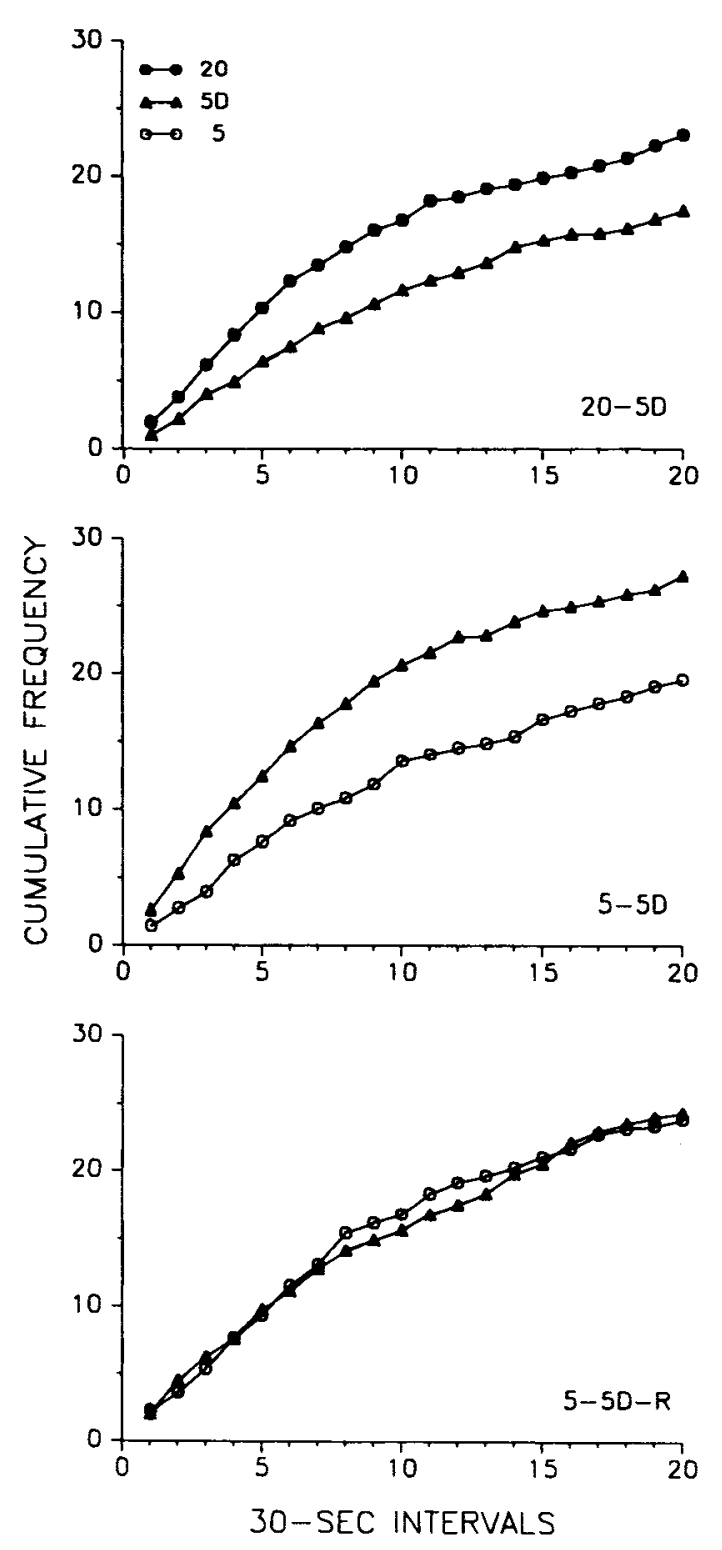

Figure 6. Mean number of responses in extinction to the two colors by the three groups of Experiment 5.

\section{Results}

In Figure 6, the test performance of the three groups is plotted in terms of the mean cumulative number of responses to each target in successive 30 -sec intervals. An overall analysis of variance yielded neither a significant group effect $(F<1)$ nor a significant stimulus effect $(F<1)$, but a significant group $\times$ stimulus interaction $[F(2,33)=6.76, p=.0035]$. The curves for Group 5-5D show a preference for the dotted target, but the curves for Group 20-5D show a preference for the

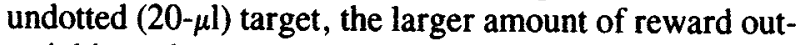
weighing whatever advantage was conferred by the dot. In separate analysis, the preference for the dotted over the undotted target in Group 5-5D proved to be signifi- cant $[F(1,11)=8.21, p=.0154]$; the preference for the undotted $20-\mu \mathrm{l}$ color over the dotted $5-\mu \mathrm{l}$ color in Group 20-5D fell short of significance at the conventional $5 \%$ level $[F(1,11)=4.05, p=.0692]$, although 10 of the 12 animals clearly preferred the undotted $20-\mu$ l color ( $p=.038$, two tails).

That the function of the dot in the 5-5D training was not simply to reduce delay of reward (and thus to increase the associative strength of Color $B$ ) is shown by the performance of Group 5-5D-R, which preferred neither target $(F<1)$. A combined analysis of the results for Groups 5-5D and 5-5D-R yielded both a significant preference for the dotted versus the undotted training color independently of extinction conditions $[F(1,22)=5.63, p$ $=.0268]$ and a significant preference for the dotted versus the undotted extinction color independently of training conditions $[F(1,22)=4.34, p=.0492]$. These results can be understood on the assumption that the associative strength of the color dotted in training grew more rapidly than that of the undotted color, with the dot itself acquiring associative strength at the same time. In Group 5-5D, the two effects were confounded in the test, working together to produce a substantial difference in performance. In Group 5-5D-R, the two effects were opposed, canceling each other completely.

The associative strength of a dotted color may be increased by the dot because the dot serves to produce closer contiguity between color and sucrose. It is possible also that second-order conditioning may play a role: If the dot itself is quickly conditioned in consequence of its close contiguity with the sucrose, the advantage of the dotted color may lie in contiguity with the dot rather than in closer contiguity with the sucrose. In this view, a lack of or a sharply reduced preference for the $20-\mu$ l color as compared with the 5- $\mu$ l color when both are dotted (Experiments 1 and 4.1) may be due to the close contiguity of both colors with the dot rather than to overshadowing, but if that were the case, we might expect a preference for the 5- $\mu \mathrm{l}$ color when it is more frequently encountered in training (which was not found in Experiments 2 and 4.2). Although these matters well deserve study, our primary interest here was to find a suitable method of measuring the effect of amount of reward uncontaminated by difference in delay, which dotting the 5 - $\mu$ l alternative alone did not seem to provide; although delay may have been equated, a strong preference for the dot in testing made it seem likely that the effect of amount was underestimated. If dots were to be used, both alternatives would have to be dotted.

\section{EXPERIMENT 6}

In the first part of this experiment, which will be referred to as Experiment 6.1, dots were used again in an effort to equate delay, but odors were substituted for the colors on the assumption that the dots would be less likely to overshadow odors than colors (Couvillon \& Bitterman, 1982). Animals were trained with targets differing in odor 
that were undotted for one group (ND-ND) and dotted for another (D-ND), after which both groups were tested with undotted targets. The second part, referred to as Experiment 6.2 , was required by the outcome of the first. A single group (D-D,ND) was trained with dotted targets labeled with a single odor that contained $5 \mu \mathrm{l}$ of sucrose, then tested with dotted and undotted targets labeled with the same odor.

\section{Method}

Subjects. The subjects were 24 foragers from our own hives, all experimentally naive.

Procedure. The targets were covered petri dishes of gray plastic, $5.5 \mathrm{~cm}$ in diameter. In each cover, eight equally spaced holes, $.5 \mathrm{~cm}$ in diameter, were drilled at the outer circumference. The dishes themselves contained cotton batting that was impregnated either with the odor of peppermint or with the odor of geraniol. In all, four sets of targets were used in the training that were distinguished by odor and by the presence or absence of a painted white dot, $4 \mathrm{~mm}$ in diameter as before. The covers of the targets used on each visit were washed and exchanged for others in the same set after the visit in order to balance extraneous stimuli. For purposes of pretraining in Experiment 6.1 only, there was an additional set of targets, each of which was scented with both peppermint and geraniol. The two-window situation was used.

In Experiment 6.1, two groups of animals $(n=8)$ were trained in the same balanced way as were Groups ND-ND and D-ND in Experiment 4.1, except that the two odors were substituted for the two colors. In an average of 10.1 training visits, Group ND-ND averaged 23.9 trials with the $20-\mu$ l odor and 24.0 trials with the $5-\mu l$ odor. The corresponding values for Group D-ND were 9.8, 23.9 , and 23.9. The extinction test that followed the training also was the same as before.

In Experiment 6.2, Group D-D,ND $(n=8)$ was trained with dotted targets that always were labeled with the same odor (peppermint for half the animals, geraniol for the rest) and always contained 5- $\mu$ l of sucrose-an average of 25.2 trials in an average of 2.1 visits. Then they were tested in the usual way, with two targets labeled with the odor used in training, one dotted and the other undotted.

\section{Results}

The extinction performance of the two groups of Experiment 6.1 is compared in Figure 7. As may be seen in the curves, both groups responded more to the 20- $\mu$ l odor than to the 5- $\mu$ l odor. Analysis of variance yielded a significant stimulus effect $[F(1,14)=34.57$, $p<.0001$, with neither a significant group effect $(F<1)$ nor a significant group $\times$ stimulus interaction $[F(1,14)=2.19, p=.1607]$. Separate analyses showed significant stimulus effects in both Group ND-ND $[F(1,7)$ $=12.01, p=.0105]$ and Group D-ND $[F(1,7)=22.67$, $p=.0021]$. On the assumption that the dots equate delay of reward, the clear preference for the $20-\mu \mathrm{l}$ odor found in Group D-ND can be attributed entirely to the difference in amount of reward, although the similar performance of the two groups suggests that even without dots there may be no difference in delay of reward to be concerned about-at least for targets like the odor targets, the eight relatively large holes drilled in the outer circumference of each serving perhaps to define more closely the locus of the centered reward.

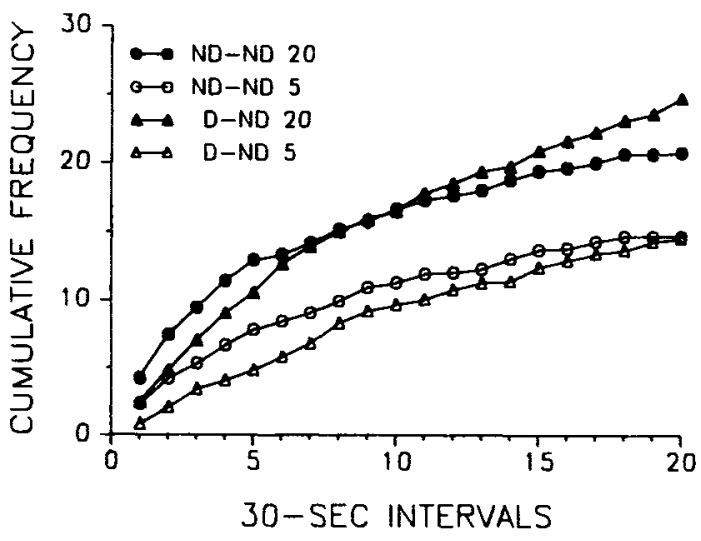

Figure 7. Mean number of responses in extinction to the 20- and 5- $\mu$ l odors by Groups ND-ND and D-ND of Experiment 6.1.

Another possibility to be considered is that delay was confounded with amount for both groups, because the dots were overshadowed by odor or other target properties and hence played no role at all. Evidence that the dots were, in fact, perceived is provided by Experiment 6.2. Plotted in Figure 8 is the test performance of Group D-D,ND, which showed a significant preference for the dotted target $[F(1,7)=14.23, p=.0070]$. The equivalent performance of the two groups of Experiment 6.1 may be taken to mean, therefore, that there is no delay problem to be concerned about, at least with targets configured like those used for work with odors.

\section{DISCUSSION}

Our purpose in these experiments, which are summarized in Table 1, was to find a way of studying the effect of amount of reward that would be uncontaminated by the possibility of a confounded difference in delay of reward stemming from a difference in the detectability of the two amounts. Neither of two methods employed to equate delay proved to be satisfactory in experiments with

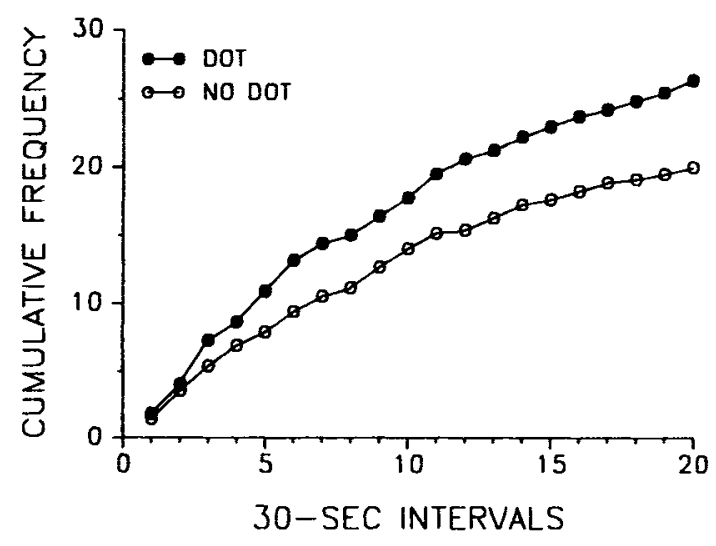

Figure 8. Mean number of responses in extinction to the training (dot) and novel (no dot) targets by Group D-D,ND of Experiment 6.2. 
targets differing in color. One of them, which was to reduce the size of the targets on which the drops of sucrose were presented, impaired color discrimination, perhaps because the salience of the colors was reduced. The second method, which was to mark the location of the reward on each target with a white dot, also impaired color discrimination for reasons that are not completely understood, although overshadowing probably plays some role. The only substantial indication of an effect of amount of reward independent of delay in the color work was the preference shown by Group 20-5D of Experiment 5 for the undotted $20-\mu \mathrm{l}$ color over the dotted 5- $\mu$ l color, which (given the attractiveness of the dot shown by Group 55D) probably underestimated the effect. The dot technique certainly is interesting for what it may contribute to the analysis of discriminative learning in honeybees, but a cleaner way will have to be found to eliminate the possibility of amount-correlated differences in delay of reward when colored stimuli are used.

As already noted, the odor results of Experiment 6 suggest that there is no delay problem to be concerned about, at least with the targets used in that experiment. The conclusion is based (1) on the evidence from the performance of Group D-D,ND that the dots were, in fact, perceived; (2) on the assumption that the dots eliminated any possibility of differential delay; and (3) on the closely similar performance of Group ND-ND, which was trained without dots, to that of Group D-ND, which was trained with dots. For odor, we do then seem to have a method of studying amount of reward uncontaminated by the possibility of differential delay, and one way of evaluating the results obtained thus far for color would be to repeat some of the color experiments with odor. The odor results might parallel the color results, supporting an equalasymptote, nonrepresentational interpretation, which would suggest that differential delay did not, in fact, play a significant role in the color experiments. If the odor results were different, further effort would be required to rule out the possibility that the color results were contaminated by delay effects, although that might not be the only reason for the difference. Another possibility to be considered would be that color and odor are processed differently.

If amount of reward is detected by the animals in terms of the duration of feeding, strength of association might be thought to increase as a function of the duration of concurrent color-taste or odor-taste stimulation, although it has been reported that honeybees learn nothing about the color (Grossmann, 1971; Opfinger, 1931) or the odor of a target (Opfinger, 1949) while feeding. It may be, too, that target properties are associated after ingestion with different sensory consequences of having taken different amounts of reward. There is evidence that honeybees learn about certain features of a feeding place on departure from it (Gould, 1988; Grossmann, 1970)-which might imply a degree of uniqueness in the learning of honeybees (Gould, 1986), were it not for some analogous results for color obtained in work with pigeons (Hearst, 1989). If, as Gould (1986) has claimed, honeybees learn about certain features of a feeding place only on arrival and about other features only on departure, the effects of varying amount of reward may not be the same for all stimuli. Although it is difficult to control exposure to stimuli in work with free-flying foragers, there is a proboscisextension technique for harnessed bees (Bitterman, Menzel, Fietz, \& Schäfer, 1983) that should provide useful information at least about the conditioning of odors presented before, during, and after various durations of feeding; it may be significant that efforts to condition visual stimuli with the same technique have been entirely unsuccessful (Walker, Baird, \& Bitterman, 1989).

As has already been indicated, the implications of the results reported here go beyond the question of how the performance of honeybees is controlled by amount of reward. They have important implications also for a promising theory of discriminative learning with which it has been possible thus far to simulate-quantitatively and with considerable accuracy - the performance of honeybees in a wide array of relatively complex choice problems (Couvillon \& Bitterman, 1987, 1988, 1989). The strategy in developing the theory was to begin with the simplest assumptions adequate to the data and then to enrich the theory as necessary to deal with the results of new experiments deliberately designed to test its limits. Although the dot experiments were carried out for other reasons, the overshadowing results do seem to present a serious challenge to the traditional independence assumption incorporated in the theory, according to which the components of a compound stimulus gain associative strength independently with reinforcement of the compound. Other instances of overshadowing have already been successfully accommodated (Couvillon \& Bitterman, 1989), but what seems to be the overshadowing of colors by dots in Experiments 1 and 4.1 suggests a new set of experiments that may well require a fundamental revision of the theory.

\section{REFERENCES}

Bitterman, M. E., Menzel, R., Fietz, A., \& Schäfer, S. (1983) Classical conditioning of proboscis extension in honeybees (Apis mellifera). Journal of Comparative Psychology, 97, 107-119.

Buchanan, G. M., \& Bitterman, M. E. (1988). Learning in honeybees as a function of amount and frequency of reward. Animal Leaming \& Behavior, 16, 247-255.

Buchanan, G. M., \& Bitterman, M. E. (1989). Leaming in honeybees as a function of amount of reward: Tests of the equal-asymptote assumption. Animal Learning \& Behavior, 17, 475-480.

Couvillon, P. A., \& Bitterman, M. E. (1982). Compound conditioning in honeybees. Journal of Comparative \& Physiological Psychology, 96, 192-199.

Couvillon, P. A., \& Bitterman, M. E. (1984). The overlearningextinction effect and successive negative contrast in honeybees (Apis mellifera). Journal of Comparative Psychology, 98, 100-109.

Couvillon, P. A., \& Bitterman, M. E. (1987). Discrimination of color-odor compounds by honeybees: Tests of a continuity model. Animal Learning \& Behavior, 15, 218-227. 
Couvillon, P. A., \& Bitterman, M. E. (1988). Compound-component and conditional discrimination of colors and odors by honeybees: Further tests of a continuity model. Animal Learning \& Behavior, 16, 67-74.

Couvillon, P. A., \& Bitterman, M. E. (1989). Reciprocal overshadowing in the discrimination of color-odor compounds by honeybees: Further tests of a continuity model. Animal Learning \& Behavior, 17, 213-222.

Couvillon, P. A., Klosterhalfen, S., \& Bitterman, M. E. (1983). Analysis of overshadowing in honeybees. Joumal of Comparative Psychology, 97, 154-166.

Gould, J. L. (1986). The biology of learning. Annual Review of Psychology, 37, 1163-1192.

Gould, J. L. (1988). Timing of landmark learning by honeybees. Jour nal of Insect Behavior, 1, 373-378.

GrossmanN, K. E. (1970). Erlemen von Farbreizen an der Futterquelle durch Honigbienen während des Anflugs und während des Saugens. Zeitschrift für Tierpsychologie, 27, 553-562.

GrossmanN, K. E. (1971). Belohnungsverzögerung beim Erlernen einer Farbe an einer Künstlichen Futterstelle durch Honigbienen. Zeitschrift für Tierpsychologie, 29, 28-41.
Hearst, E. (1989). Backward associations: Differential learning about stimuli that follow the presence versus the absence of food in pigeons. Animal Learning \& Behavior, 17, 280-290.

LeE, Y., \& Bitterman, M. E. (1990). Learning in honeybees (Apis mellifera) as a function of amount of reward: Acquisition measures. Journal of Comparative Psychology, 104, 152-158.

Opfinger, E. (1931). Über die Orientierung der Biene an der Futterquelle. Zeitschrift fur vergleichende Physiologie, 15, 431-487.

Opfinger, E. (1949). Zur Psychologie der Duftdressuren bei bienen. Zeitschrift für vergleichende Physiologie, 31, 441-453.

Walker, M. M., Baird, D. L., \& BitTerman, M. E. (1989). Failure of stationary but not of flying honeybees (Apis mellifera) to respond to magnetic field stimuli. Journal of Comparative Psychology, 103, 62-69.

Walker, M. M., LeE, Y., \& BitTerman, M. E. (1990). Transfer along a continuum in the discriminative learning of honeybees (Apis mellifera). Journal of Comparative Psychology, 104, 66-70.

(Manuscript received January 5, 1990; revision accepted for publication June 15,1990 .) 